\title{
CONTRIBUIÇÕES DA ECONOMIA COMPORTAMENTAL PARA O DIREITO EMPRESARIAL
}

\author{
BEHAVIORAL ECONOMICS CONTRIBUTIONS TO COMMERCIAL LAW
}

\author{
Rafael Bianchini Abreu Paiva* \\ Luiza Silva Balthazar**
}

\begin{abstract}
Resumo:
$\mathrm{O}$ artigo tem como objetivo apresentar as principais contribuições da Economia Comportamental, traçando um paralelo com o Direito. Para tanto, o artigo está dividido em seis partes: 1. Hipóteses comportamentais relativas ao homo economicus das escolas de pensamento dominantes; 2. Críticas ao homo economicus; 3. Contribuições da Economia Comportamental, com destaque para os vieses acarretados pela ancoragem, excessivo otimismo, inércia (status quo bias), framing, além da importância das tentações e do comportamento de manada. Esta parte busca relacionar os conceitos introduzidos pela Economia Comportamental e exemplos aplicáveis ao cenário jurídico-empresarial. Observa-se que o direito positivado e a jurisprudência frequentemente adotam implicitamente a hipótese da racionalidade forte, ignorando aspectos essenciais do comportamento humano; 4. Indícios de necessidade de aprimoramento nos incentivos de mercado; 5. Estudo sobre a crise de 2008 no mercado de derivativos cambiais, analisando criticamente a jurisprudência e a resposta dos reguladores à luz da Economia Comportamental. Por fim, no item 6 são feitas as considerações finais.
\end{abstract}

Palavras-chave: Homo economicus. Racionalidade forte. Economia comportamental. Otimismo. Ancoragem. Inércia. Framing. Direito Comercial. Derivativos.

\begin{abstract}
:
This paper aims to present the main contributions of Behavioral Economics, drawing a parallel with Law. For this purpose, the article is divided in six parts: 1. Behavioral hypothesis related to homo economicus from the mainstream schools of thought; 2. Critics to homo economicus; 3. Contributions of Behavioral Economics, highlighting the bias caused by anchoring, excessive optimism, status quo bias, framing, besides the importance of the temptations and the herd behavior. This topic aims to relate the concepts introduced by Behavioral Economics and examples applicable to the legal and corporate scenarios. The written Law and case Law frequently adopt implicitly the strong rationality hypothesis, ignoring essential aspects of human behavior; 4 . Evidence of the need of improvement in market incentives; 5. Study on the 2008 crisis in the foreign exchange derivatives Market, analyzing critically case Law and the answer of the regulators in accordance with the Behavioral Economics. Finally,
\end{abstract}

Bacharel em Economia (Unicamp), Bacharel, Mestre e Doutorando em Direito (USP) e Analista do Banco Central do Brasil.

** Bacharela em Administração Empresarial (UDESC) e em Direito (UFSC), Mestranda em Direito Comercial (USP) e advogada. 
item 6 presents final considerations.

Keywords: Homo economicus. Strong rationality. Behavioral Economics. Optimism. Anchoring. Status quo bias. Framing. Commercial Law. Derivatives.

1. As hipóteses comportamentais do mainstream econômico

A análise econômica tradicional parte do individualismo metodológico, tendo como unidade básica o homo economicus, cujas características foram construídas a partir do utilitarismo, ramo da filosofia moral. O homo economicus é um agente que visa a maximizar egoisticamente um objetivo individual, como o lucro ou o bem-estar. Devido a restrições exógenas, como preços de mercado, tecnologias disponíveis e dotação inicial de recursos, a maximização do bem-estar depende de elevado grau de racionalidade, o que, por sua vez, depende das seguintes hipóteses sobre a tomada de decisões:

i. Completude das preferências: confrontados com opções diferentes, os agentes econômicos sempre sabem dizer quais escolhas são preferíveis ou se são indiferentes a duas ou mais alternativas;

ii. Transitividade: os agentes não tomam decisões inconsistentes, ou seja, se consideram A preferível a B e B preferível a C, certamente consideram A preferível a $\mathrm{C}$;

iii. Não saciedade: o aumento de opções disponíveis para um agente não gera diminuições de bem-estar. Na pior das hipóteses, um leque mais amplo de possibilidades não aumenta o bem-estar;

iv. Erros não-sistemáticos: os agentes econômicos podem errar nas previsões, mas incorporam os erros nas previsões futuras, ou seja, os erros não são sistemáticos (PINDYCK; RUBINFELD, 2005).

Nos modelos econômicos, essa racionalidade forte é representada como se todos os agentes, independentemente do porte econômico ou escolaridade, executassem complexos cálculos matemáticos antes de tomar decisões. Evidentemente se sabe que a maioria dos indivíduos não é capaz de fazer os cálculos presentes nos modelos. Entretanto, agentes racionais aprendem com os erros ao longo do tempo, adaptando-se aproximandose dos comportamentos maximizadores ao longo do tempo.

\section{Nem tão egoísta, nem tão racional}

Hodgson (2013) critica o utilitarismo porque parte de pressupostos comportamentais não falseáveis e, portanto, não científicos. Ademais, a maximização da utilidade individual feita pelo homo economicus é geral a ponto de descrever o 
comportamento de seres de qualquer espécie, não representando nada de específico dos seres humanos.

$\mathrm{Na}$ análise econômica convencional, seres racionais são levados a cooperar por entenderem que isso é um meio de levá-los à maximização de seus objetivos individuais. Mas, estudos feitos com simulações computacionais comprovaram que a cooperação, embora eficiente, pode surgir inclusive da interação de seres unicelulares (AXELROD, 1984).

Além disso, estudo recente de psicologia comportamental se contrapõe à hipótese de que os seres humanos seriam totalmente egoístas e maximizadores ao concluir que o processo de seleção natural favoreceu seres humanos mais aptos a cooperar e que nem sempre agem a maximizar o bem-estar comum. Isso porque a maioria das pessoas age com o objetivo de cumprir determinados deveres morais, mesmo que o estrito cumprimento desses deveres não resulte em um bem maior (EVERETT, 2016).

Ao contrário do que seria de se esperar a partir da hipótese da racionalidade forte, Dovern e Jannsen (2015) constataram que os agentes econômicos cometem erros sistemáticos ao longo do ciclo econômico. Antes das crises, os agentes costumam ser excessivamente otimistas e, uma vez iniciada a recessão, os agentes se tornam excessivamente pessimistas. Em muitos casos, são choques não antecipados - como aumento na demanda externa ou redução dos estoques indesejados - que precedem a recuperação.

As abordagens alternativas ao mainstream procuram levar em conta aspectos biológicos, psicológicos e sociais do comportamento humano, cabendo destacar as hipóteses da racionalidade limitada da economia comportamental e da racionalidade fraca ou orgânica da escola evolucionista. Ao se relaxar a hipótese da racionalidade forte, ineficiências podem subsistir mesmo com oferecimento de informações completas, pois essas podem ser mal compreendidas, vistas como não confiáveis ou distantes das escolhas que o cidadão enfrenta. Neste sentido, mesmo que não existam falhas de mercado, o livre mercado em geral não resulta em soluções eficientes.

\section{A economia comportamental}

Para Kahneman (2012), o ser humano possui dois diferentes sistemas de pensamento que se influenciam reciprocamente. O Sistema 1 caracteriza-se pelo pensamento rápido e ações automáticas, como dirigir por uma estrada conhecida ou fazer contas simples. O Sistema 2, por sua vez, responsabiliza-se pelas ações mais trabalhosas, como fazer uma manobra difícil ou executar cálculos complexos. A divisão de trabalho entre os dois sistemas age no sentido de minimizar o esforço e otimizar o desempenho. $\mathrm{O}$ arranjo funciona bem na maior parte do tempo, pois o Sistema 1 geralmente é bom no 
que faz: suas previsões de curto prazo são precisas e suas reações iniciais a desafios são rápidas e normalmente apropriadas. Entretanto, o Sistema 1 tem vieses, que resultam em erros sistemáticos que ele tende a cometer em circunstâncias específicas (KAHNEMAN, 2012, p. 34).

Daniel Kahneman exerceu grande influência sobre Richard Thaler e Cass Sunstein, referências em economia comportamental e que partem da dicotomia entre os sistemas automático e reflexivo, análogos aos sistemas 1 e 2 de Kahneman. No bestseller "Nudge: Improing Decisions about Health, Wealth and Happiness" (THALER; SUNSTEIN, 2008), os autores sistematizam alguns desvios cognitivos e psicológicos que fazem do ser humano alguém diferente do homo economicus. Por essa razão, o libertarianismo em sua versão pura, tal como defendido por muitos economistas, resulta frequentemente em soluções ineficientes e socialmente indesejáveis. Por outro lado, os autores tampouco negam a importância do egoísmo e de mecanismos de incentivos adequados. Por essa razão, Thaler e Sunstein defendem na obra a ideia de um paternalismo libertário, conceito que leva em conta os limites da racionalidade humana e procura antecipar-se a comportamentos irracionais.

Este tópico apresentará os principais aspectos da economia comportamental tendo como referência a obra de Thaler e Sunstein, sem, no entanto, restringir-se a ela.

\subsection{Vieses e distorções de percepção}

Os principais vieses na formação de expectativas seriam a ancoragem, o otimismo excessivo, a inércia e o framing, conceito ligado à maior propensão das pessoas escolherem aquilo que lhes é apresentado.

\subsubsection{Ancoragem}

$\mathrm{O}$ viés da ancoragem se caracteriza por "considerar um valor particular para uma quantidade desconhecida antes de estimar essa quantidade". (KAHNEMAN, 2012, p. 152-153). A ancoragem é importante técnica de negociação de preços e valores contratuais.

Desde a década de 1970, diversos autores trabalham em estudos para demonstrar a importância de tais âncoras na tomada de decisão. Northcraft e Neale (1987) comprovam empiricamente que a apresentação de uma lista de preços juntamente de outras informações exerce forte influência tanto sobre amadores, quanto sobre especialistas, ainda que os dois grupos tenham tido a impressão que a lista de preços foi irrelevante para o seu cálculo final.

A ancoragem também exerce influência decisiva na quantificação de danos morais. Em geral, os magistrados se pautam pelo chamado binômio reparação e punição, 
ou seja, a quantia arbitrada deve ser capaz de reparar a vítima e servir como punição ao causador do dano, tendo também caráter pedagógico de evitar a reincidência no erro.

Ocorre que, conforme demonstrado por Chapman e Bornstein (1996) em simulações envolvendo a mesma situação fática e pedidos de indenização que variavam de cem a um bilhão de dólares, existe uma correlação positiva forte entre aquilo que é pedido pelo autor (âncora) e a indenização que é de fato concedida pelo juiz em casos de danos pessoais. A repetição de valores em casos distintos começou a ser notada pelos próprios magistrados, como se pode notar nesta observação do Ministro Paulo de Tarso Sanseverino (BRASIL, 2011b): “a valorização do bem ou interesse jurídico lesado é um critério importante, mas deve-se ter o cuidado para que não conduza a um engessamento excessivo das indenizações por prejuízos extrapatrimoniais".

O apontado "engessamento" indica a preocupação da corte na repetição dos valores, motivado inclusive pela necessidade de uniformização da jurisprudência nacional. Por outro lado, a convergência no valor das indenizações pode resultar de uma estratégia das partes, as quais, ao colacionarem diversos julgados semelhantes em uma petição, exercem influência sobre o arbitramento do juiz. O mesmo ocorre nas sentenças arbitrais, como demonstrado empiricamente por Christopher Drahozal (2004).

\subsubsection{O viés otimista}

Segundo a neurocientista Tali Sharot (2015), o processo evolutivo teria favorecido pessoas com um viés moderadamente otimista do futuro, pois em alguma medida o otimismo é profecia autorrealizadora. As pessoas mais otimistas tendem a adotar comportamentos que se enquadram no estereótipo das pessoas bem-sucedidas, enquanto pessoas mais pessimistas tendem a adotar comportamentos inversos. Ainda assim, a partir de certo ponto o otimismo tornar-se-ia disfuncional: com a certeza de serem bemsucedidas, as pessoas deixariam de tomar as precauções necessárias e assumiriam riscos excessivos. O otimismo resultaria de duas ilusões cognitivas: a superioridade e o ponto cego.

A superioridade decorre das pessoas dificilmente se verem entre as pessoas de menor desempenho. É frequente que mais da metade dos estudantes, trabalhadores e empresários se considere acima da mediana, embora por definição apenas metade de um grupo esteja acima da mediana. Nos contratos, isso significa que a maioria das pessoas tende a subestimar a probabilidade de estar no grupo que não obtém resultado esperado com a contratação.

O ponto cego ou introspecção, por sua vez, é uma característica segundo a qual as pessoas tendem a avaliar melhor aos outros que a si próprias e, mesmo que se esforcem, não conseguem ter uma avaliação isenta de si. Isso explica, por exemplo, a 
necessidade de o CPC elencar hipóteses de suspeição (art. 145) e impedimento (art. 144) de juízes e ainda assim abrir a possibilidade de que o juiz se declare suspeito por motivo de foro íntimo, sem necessidade de declarar suas razões (art. 145, $\S 1^{\circ}$ ).

Uma consequência prática do viés otimista é que tendemos a nos adaptar rapidamente a resultados melhores que os esperados. Por outro lado, os resultados negativos tendem a ser incorporados com mais lentidão. Sharot (2015) também constata que, devido às limitações cognitivas, o excesso de parâmetros de avaliação pode resultar em escolhas subótimas, pois as pessoas passam a focar nesses parâmetros, deixando de lado parâmetros tácitos.

Há alguns dados empresariais que apoiam esse pensamento (IBGE, 2016). No Brasil, cerca de um quinto das empresas não sobrevive ao primeiro ano e mais da metade não completa cinco anos de existência. Embora a taxa de sobrevivência das empresas seja positivamente correlacionada com crescimento econômico, o índice de sobrevivência das empresas tem um componente estrutural. Entre 2008 e 2012, apesar das mudanças expressivas na taxa de crescimento média do Produto Interno Bruto (PIB) entre o ano de criação da empresa e o ano seguinte, a taxa de sobrevivência ao primeiro ano manteve-se relativamente estável. De fato, neste período ocorre um efeito contra intuitivo: entre 2008 e 2009, a despeito do maior ritmo de crescimento do PIB, há queda na taxa de sobrevivência das empresas. Já entre 2010 e 2012, embora o crescimento do PIB tenha desacelerado, houve aumento na taxa de sobrevivência das empresas. Isso é um indício de que a crise de 2008/2009 tenha fomentado pessimismo defensivo, ao passo que aceleração do crescimento do PIB entre 2010 e 2011 tenha exercido efeito oposto, induzindo um grau de otimismo exagerado nos empresários (Gráfico 1).

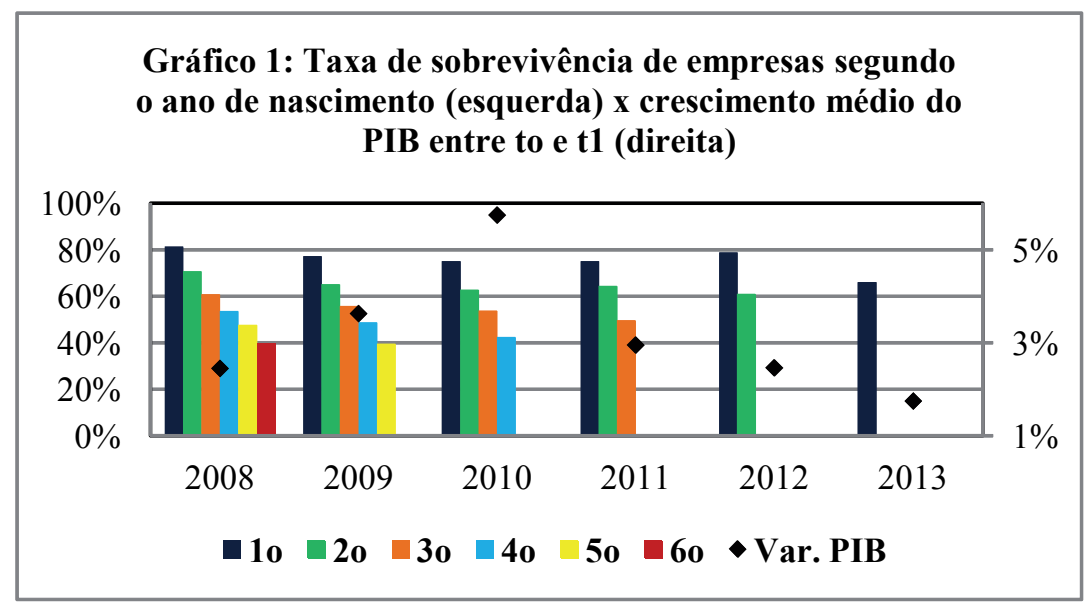

Fonte: IBGE 
Outro aspecto interessante evidenciado no Gráfico 1 é que, grosso modo, durante os primeiros cinco anos de existência, cerca de $20 \%$ das empresas estabelecidas fecham as portas anualmente. Essa realidade contrasta fortemente com as projeções dos próprios empresários, conforme pesquisa realizada pelo Serviço Brasileiro de Apoio às Micro e Pequenas Empresas (SEBRAE, 2014) realizada com 1.300 empresas. A grande maioria (63\%) tem planos de se expandir, enquanto apenas 5\% prevê vender o negócio e quase ninguém espera encerrar as atividades. A pesquisa realizada pelo SEBRAE-SP também revelou que, entre as empresas em funcionamento, 31\% dedicaram mais de 6 meses ao planejamento prévio dos negócios, contra $18 \%$ das empresas encerradas. Isso corrobora a hipótese de que, quando excessivo, o otimismo passe a ser disfuncional.

Além das pesquisas de mortalidade empresarial, é possível vislumbrar o excessivo otimismo na formação dos contratos de franquia. Conforme determina a Lei n. $8.955 / 1994$, art. $3^{\circ}$, o franqueador é obrigado a entregar ao franqueado, com 10 dias de antecedência, a circular de oferta de franquia (COF) (BRASIL, 1994). Este documento, com informações essenciais ao negócio, visa a dar ao franqueado a oportunidade de avaliar o negócio, mitigando o viés otimista.

Analisando 41 julgados do Tribunal de Justiça do Estado de São Paulo (TJSP) com as palavras-chave "franquia" e "risco do negócio", observa-se que apenas três deles a rescisão contratual foi pleiteada pela franqueadora. Por outro lado, em 34 julgados foi o franqueado quem pretendia a rescisão ou anulação do negócio. A anulação era invariavelmente requerida com o argumento de que a COF estava incompleta ou não fora entregue. Em 17, houve pleito no sentido de caracterização de inadimplemento contratual da franqueadora que teria resultado em prejuízo do franqueado.

Em nenhum dos casos houve anulação do negócio jurídico, pois se considerou que a COF teria cumprido com os requisitos legais ou que negócio foi convalidado por terem se passado mais de dois anos sem qualquer reclamação. A rescisão do contrato operou-se em 10 dos 41 casos. Os demais 31 casos deram ganho de causa à franqueadora, sendo 28 deles com base na teoria do risco de negócio. A fundamentação dos acórdãos é bastante clara no sentido de que, ao iniciar uma franquia, as partes assumem o risco inerente à atividade empresarial.

Percebe-se, portanto, que embora a legislação tenha previsto um mecanismo para lidar com possível otimismo excessivo na formação do contrato de franquia, não raramente os franqueados se voltam contra a franqueadora para exigir parte do esperado sucesso, ainda que o fracasso dos negócios se deva também à sua própria má-gestão. 


\subsubsection{O viés da inércia (status quo bias)}

O viés da inércia caracteriza-se pela tendência humana a manter as coisas como estão, ou seja, aceitar o padrão ou não tomar determinadas medidas a menos que estritamente necessário. Para Richard H. Thaler e Cass R. Sunstein (2008), contratos com renovação automática são um caso típico de exploração econômica do viés inercial. Embora seja mais comum em relações consumeristas, o viés da inércia pode ser observado também nas relações empresariais.

Tradicionalmente, os economistas veem a introdução de regras padrão (default rules) nos contratos como uma forma de diminuir custos de transação na elaboração e interpretação de cláusulas mais complexas e como uma forma de as partes não revelarem informações que julgam estratégicas. Para Russel Korobkin (1998), essas regras padrão também são resultado de comportamento inercial dos agentes econômicos, que tendem a preferir o status quo. Neste sentido, as cláusulas padrão influenciam nas escolhas das partes, o que pode gerar ineficiências. Portanto, a arquitetura contratual deve tentar se antecipar aos possíveis resultados da inércia.

Os contratos por prazo determinado pressupõem que as partes cumprirão aquele período e, findo tal lapso temporal, poderão renovar a relação ou extinguila por completo, sendo que caso nada seja feito (inércia), esses passam a valer por prazo indeterminado. Já os contratos por prazo indeterminado podem ser rescindidos unilateralmente, desde que respeitado o aviso prévio e que tal prazo seja compatível com o vulto dos negócios. ${ }^{1}$

Porém, alguns contratos exigem um tempo mínimo de duração ou investimentos periódicos para sua execução, fazendo com que o prazo determinado seja mais indicado. Nessas ocasiões, muitas vezes o contrato é firmado por prazo determinado com cláusula de renovação automática. A duração é determinada e, findo aquele período sem manifestação das partes, inicia-se a contagem de um novo período de mesma duração.

Percebe-se que tal cláusula considera que há chance de as partes não se atentarem à expiração do prazo e o contrato se tornar por prazo indeterminado. A questão que se coloca é se a renovação sucessiva do contrato por períodos iguais têm o condão de descaracterizar sua natureza de prazo determinado.

Por vezes entende-se que não há descaraterização da disposição contratual (MINAS GERAIS, 2015), mas em outros julgados, julgou-se pela inaplicabilidade do

Lei n. 10.406/02 (Código Civil), art. 720. Se o contrato for por tempo indeterminado, qualquer das partes poderá resolvê-lo, mediante aviso prévio de noventa dias, desde que transcorrido prazo compatível com a natureza e o vulto do investimento exigido do agente. Parágrafo único. No caso de divergência entre as partes, o juiz decidirá da razoabilidade do prazo e do valor devido. 
prazo determinado, caso não esteja expresso o prazo pelo qual o contrato passará a vigorar depois de expirado o primeiro lapso temporal previsto (SÃO PAULO, 2015). A previsão que visa a eliminar eventuais efeitos inerciais deve ser clara e precisa, portanto.

\subsubsection{Framing}

$\mathrm{O}$ efeito de framing (em português enquadramento) ocorre quando a apresentação de uma mesma informação de diferentes maneiras altera a decisão relativa ao problema. Diferentemente do homo economicus, as pessoas são influenciadas pela forma (moldura, frame) em que a informação é apresentada. Para Amos Tversky e Daniel Kahneman (1981), isso ocorre devido às imperfeições nas percepções e na tomada de decisões.

A forma pela qual lojistas podem repassar os custos relativo às vendas com cartão de crédito é um interessante caso de framing. Os lojistas devem repassar às administradoras de cartões de crédito um percentual sobre as vendas. Há duas formas de se repassar esse custo aos compradores: cobrando um adicional sobre as compras com cartão ou oferecendo desconto de mesmo valor para quem paga em dinheiro.

Thaler e Sunstein (2008) indicam que a propensão a realizar compras com cartões de crédito é menor quando os lojistas cobram adicional sobre as vendas com cartão de crédito. No Brasil, o STJ havia assentado entendimento de que é vedada a diferenciação de preços em razão do método de pagamento, uma solução ineficiente por obrigar os consumidores que pagam em dinheiro subsidiem aqueles que realizam compras com cartões. Porém, a Lei n. 13.455/2017 possibilitou entendimento contrário e, portanto, os comerciantes estão livres para diferenciar os preços, seja por método ou prazo de pagamento.

Em caso similar, o STJ foi instado a decidir sobre a possibilidade de instituições de ensino concederem descontos caso o pagamento da mensalidade fosse feito até a data de vencimento. A ação foi movida pelo Ministério Público do Estado de São Paulo e acusava a instituição de ensino de cobrar penalidade disfarçada que ultrapassava o teto de 2\% estipulado pela Lei n. 8.078/1990 (Código de Defesa do Consumidor - CDC). Nesse caso, porém, o STJ entendeu que, além de legal, a medida deve ser incentivada, visto que se trata da técnica do encorajamento por meio de sanções positivas (BRASIL, 2016).

Portanto, observa-se que em casos semelhantes, o STJ manifestou-se de forma diferente: ora caracteriza discriminação por método de pagamento, ora trata como uma sanção positiva e prática que deve ser incentivada. 


\subsection{Tentações}

O conceito de tentação é um impulso que nos leva a fazer algo que racionalmente (na qualidade de economicus) não faríamos. São vários os exemplos cotidianos, como continuar comendo sem ter fome. Em geral, humanos têm consciência de que existem tentações e muitas vezes reconhecem estar diante de uma. Por esse motivo, é possível colocar algumas barreiras para evitar as atitudes indesejadas (retirar o alimento da mesa, por exemplo).

Estas situações caracterizam barreiras externas, ou seja, o indivíduo impõe obstáculos para impedir a ação indesejada. A lei, muitas vezes, funciona como uma barreira externa: as pessoas deixam de realizar determinados atos em razão das possíveis consequências. Existem também barreiras internas, que são limites impostos pela própria pessoa e controlados mentalmente.

No universo empresarial também se vislumbram situações de tentação. $\mathrm{Na}$ ausência de regulação, as tentações serão exploradas por agentes econômicos porque são oportunidades de ganhos. Isso explica, por exemplo, os diversos meios pelos quais se limita o poder dos agentes.

Um obstáculo externo que visa a impedir comportamentos indesejados dos agentes é a legislação do mercado financeiro, especialmente a de insider trading. Nos termos do art. 27-D da Lei n. 6.385/76, considera-se crime contra o mercado de capitais "utilizar informação relevante ainda não divulgada ao mercado, de que tenha conhecimento e da qual deva manter sigilo, capaz de propiciar, para si ou para outrem, vantagem indevida, mediante negociação, em nome próprio ou de terceiro, com valores mobiliários" (BRASIL, 1976). A partir do momento que a tentação estiver delineada, a lei serve para barrá-lo.

\subsection{Comportamento de manada}

O comportamento de manada caracteriza-se pelo poder que a influência social tem sobre os indivíduos. Cada ser humano acredita que as ações tomadas pelo grupo (a sociedade, por exemplo) sinalizam uma informação e, por isso, sentem-se pressionadas para agir da mesma forma que a maioria. Além disso, o fato de as pessoas acreditarem que os demais prestam mais atenção nelas do que realmente prestam reforça o comportamento de manada. A sensação de ser constantemente observado - e julgado inibe comportamentos diferentes do dominante.

Além disso, as pessoas têm suas ações influenciadas por eventos prévios, mesmo não tendo ciência disso. Os estudiosos do assunto chamam essa influência de priming e afirmam que "você não pode saber disso pela experiência consciente, é claro, 
mas deve aceitar a estranha ideia de que suas ações e emoções podem ser primadas por eventos dos quais nem sequer tem consciência” (KAHNEMAN, 2012, p. 70).

No que tange os contratos empresariais, o comportamento de manada é um efeito relevante, especialmente quando se conclui que parte considerável das cláusulas postas nos instrumentos são repetidas à exaustão em diversos tipos diferentes de contratos - em inglês, tais cláusulas são chamadas de boilerplate. Nas palavras de Paula Forgioni (2016, p. 85), “as vicissitudes da interpretação contratual fizeram com que se difundisse o hábito de incluir nos instrumentos contratuais (...) série de dispositivos standard ou padrão".

Em estudo sobre as cláusulas boilerplate, Marcel Kahan e Michael Klausner (1996) constatam que, embora cláusulas customizadas possam trazer benefícios, a redução dos custos de transação associada à padronização das cláusulas contratuais termina por acentuar o uso dessas cláusulas, criando um padrão de path dependence quanto mais onipresente for uma cláusula padronizada, mais importante ela tende a ser. Essa característica é reforçada pelos profissionais do direito que são contratados para redigir contratos empresariais, intensificando o comportamento de manada. Isso pode levar as empresas a se vincularem por instrumentos contratuais ineficientes, a despeito da redução de custos de transação que isso representa.

As cláusulas de que o instrumento é firmado em caráter "irrevogável e irretratável”, em geral apostas nas disposições gerais, são exemplo de cláusula padrão reforçada pelo comportamento de manada. Se tal cláusula for inserida em um instrumento de adiantamento para futuro aumento de capital (AFAC) em uma sociedade, por exemplo, ela pode trazer consequências contábeis. Conforme decisão do Processo Administrativo Sancionador (PAS) n. 8/2012 da Comissão de Valores Mobiliários (CVM), se determinado aporte for "irrevogável e irretratável", ele deve ser registrado no patrimônio líquido. Se não houver essa cláusula, deve constar no passivo.

Há situações, entretanto, nas quais, embora constem dos instrumentos contratuais, há questionamento sobre a eficácia de tais cláusulas. Em acórdão do STJ sobre rescisão unilateral de contrato de prestação de serviços advocatícios, ficou assentado que “ainda que as partes tivessem convencionado cláusulas de irrevogabilidade, por se tratar de contrato fundado na confiança, tem o mandante a faculdade de revogá-lo unilateralmente a qualquer tempo" (BRASIL, 2011b). Portanto, nem sempre os redatores dos contratos obtêm bons resultados ao "seguir o fluxo" das disposições-padrão. Não apenas porque parte das consequências são desconhecidas por eles, como a própria eficácia da disposição pode ser comprometida. 
4. Indícios de necessidade de aprimoramento nos incentivos de mercado

Para os economistas George Akerlof e Robert Shiller (2015), mesmo na ausência de falhas de mercado, soluções puras de mercado tendem a produzir manipulação e decepção. Isso ocorre porque deficiências na percepção de mundo de alguns agentes econômicos cria a possibilidade de que outros explorem essas falhas e obtenham ganho. Para os autores, os agentes podem assumir dois arquétipos: phools (neologismo com fool, ou tolo) e phishers (derivação de phishing, nome dado à fraude eletrônica que consiste na obtenção fraudulenta de dados pessoais). Os phools podem ser de dois tipos: i. informacional, que raciocinam com base em falsas informações ou, a partir de informações verdadeiras, podem ser induzidos a tirar conclusões equivocadas e ii. cognitivos, que, apesar de conseguirem identificar racionalmente as escolhas mais vantajosas, não conseguem reduzir às tentações ou são induzidos a escolher a adquirir algo diferente do que querem.

Os phishers, por sua, vez, sabem explorar as fragilidades informacionais ou cognitivas dos phools para induzi-los a tomar decisões contrárias aos seus interesses e, com isso, obter lucros extraordinários. Quando a regulação não leva em conta as possíveis fragilidades de alguns agentes, a concorrência pode forçar que outros, inicialmente neutros, se tornem phishers, pois quem têm lucros mais altos pode facilmente transformar isso em diferencial competitivo. As limitações cognitivas e emocionais não podem ser tratadas como exceções ou desvios em relação aos comportamentos racionais.

Para Thaler e Sunstein (2008), a identificação de situações em que os pressupostos comportamentais da análise econômica tradicional são fracos são um indicativo da necessidade de intervenção:

i. Alto grau de complexidade das alternativas;

ii. Baixa frequência com que a pessoa se depara com a escolha;

iii. Benefícios no curto-prazo e custos no longo-prazo;

iv. Ausência de feedback que permita a correção de percepções e estratégias;

v. Dificuldade em se conhecer a própria vontade;

vi. Dificuldade de traduzi-la em escolhas, mesmo quando os agentes conhecem a própria vontade.

Isso deve ser levado em conta na arquitetura da tomada de decisões por meio da simplificação da árvore de decisões e de um bom padrão sugerido, que incentivam o uso do sistema automático e tornam os caminhos de menor resistência socialmente desejáveis. A identificação desses caminhos, por sua vez, depende da tentativa de se antecipar possíveis erros dos agentes. Grandes bases de dados e, no caso específico do 
Direito, a jurimetria, podem auxiliar na identificação de quais escolhas são socialmente mais desejáveis.

5. Estudo de caso: os contratos de derivativos na crise de 2008

A análise das perdas incorridas por grandes empresas com os contratos de derivativos na crise de 2008, bem como a resposta da jurisprudência e dos reguladores, é um excelente estudo de caso sobre como a Economia Comportamental pode contribuir para antecipar comportamentos indesejáveis e fornecer elementos para uma regulação mais eficiente.

\subsection{Aspectos econômicos e jurídicos: breves considerações}

Derivativos são instrumentos financeiros de natureza contratual e, no Brasil, são considerados valores mobiliários, cujo valor deriva de outras grandezas, como moedas estrangeiras, taxas de juros etc. Os derivativos possuem três funções: proteção (hedge), especulação e arbitragem. O hedge ocorre quanto à contratação visa a mitigar total ou parcialmente efeitos adversos de algum indicador econômico: os exportadores (importadores) podem se proteger da queda (aumento) do dólar vendendo (comprando) dólares no mercado futuro, de modo que o resultado com derivativos compense as perdas ou ganhos resultantes da alteração da cotação. Já a especulação ocorre quando os agentes econômicos contratam esses instrumentos porque acreditam que as cotações irão se mover em uma determinada direção. Por fim, a arbitragem ocorre quando os preços no mercado à vista e de derivativos apontam para direções opostas e agentes de mercado compram ou vendem derivativos para eliminar distorções, servindo para impedir que distorções nas cotações sejam duradouras (HULL, 2005).

Na prática, as funções de proteção e especulação são apenas abstratamente cindíveis. A proteção e a especulação podem existir em uma mesma fatispécie, como ocorre, por exemplo, com o caso de excesso de hedge (overhedging), na qual a parcela do contrato que excede a cobertura tem função especulativa, de modo que a distinção entre as funções depende de um critério quantitativo. Por essa razão, Emilio Girino (2010, p. 26-31 e 271-278) entende que a função não é apta a qualificar nem influenciar a validade intrínseca dos derivativos.

A literatura especializada classifica os derivativos em três espécies contratos a termo, opções e swaps (BANK FOR INTERNATIONAL SETTLEMENTS, 2003). Em apertada síntese, nos contratos a termo uma parte se obriga a comprar, a outra a vender, um ativo subjacente a um preço específico em uma data futura. Nas opções de compra (venda), o comprador tem o direito de comprar (vender) um determinado ativo subjacente a um preço específico em uma ou mais datas futuras. Já nos swaps, como o 
próprio nome indica, há uma troca de rentabilidades. Na maioria dos negócios jurídicos, não há entrega dos ativos subjacentes, ou seja, as partes negociam apenas um diferencial de cotações. Na verdade, boa parte dos derivativos tem natureza híbrida, ou seja, mistura características de mais de uma espécie de derivativos.

Para Girino (2010), os derivativos são contratos a termo ou de execução diferida, mas não são contratos diferenciais, sempre têm referência a uma grandeza econômica real ou abstrata, em que o objeto da negociação não é exatamente o ativo subjacente, mas seu diferencial de preços entre o momento da estipulação e do momento de liquidação. Há, portanto, um elevado componente aleatório, de modo que em muitos casos não se sabe de antemão quem será o credor e o devedor e não há um limite para as perdas potenciais. $\mathrm{O}$ fato de que, a posteriori, ser possível que recaiam obrigações sobre apenas uma das partes não seria suscetível de requalificar o contrato para unilateral.

Em suma, derivativo seria contrato bilateral, de execução diferida, caracterizado por um forte e inerente componente de aleatoriedade, com referência a uma entidade econômica real ou abstrata, e como objeto o diferencial de valores no tempo da entidade econômica.

\subsection{A crise de 2008}

Entre maio de 2004 e agosto de 2008, a moeda brasileira teve apreciação progressiva e praticamente contínua frente ao dólar e outras moedas - no período, a cotação do dólar comercial caiu de $\mathrm{R} \$ 3,13$ para $\mathrm{R} \$ 1,63$, sendo que as instituições financeiras esperavam que o dólar comercial estivesse cotado em R\$ 1,65 no final de 2008 (BANCO CENTRAL DO BRASIL, 2008). Embora o boom de commodities associado ao forte crescimento econômico da China favorecesse os exportadores brasileiros, a apreciação cambial vinha agindo no sentido de diminuir sua lucratividade. Ainda assim, diversas exportadoras brasileiras tinham lucros crescentes, a despeito da queda de margens. Os negócios com derivativos de dólar trouxeram ganhos que, até então, vinham compensando as perdas resultantes da queda do dólar.

Em grande medida, a alta lucratividade do setor exportador a despeito da apreciação cambial decorria da contratação de instrumentos conhecidos como Target Accrual Range Forward (TARF) e Target Accrual Range Note (TARN), derivativos de balcão que não chegam a ser exóticos, mas que misturam características de contratos a termo e swaps. O mecanismo de funcionamento é relativamente simples: as instituições financeiras e exportadoras estabeleciam uma operação na qual as empresas venderiam dólares periodicamente - mensalmente ou semestralmente - a uma determinada taxa de câmbio (A). Se a taxa de câmbio fosse menor que A, a empresa venderia uma quantidade de dólares $\mathrm{x}$ à instituição financeira. Por outro lado, se o dólar estivesse cotado a um valor 
maior que A, a empresa venderia uma quantidade 2x de dólares. No jargão do mercado, esse mecanismo é conhecido como cláusula de alavancagem $2 \times 1$. Ademais, esses contratos contam com a existência de cláusulas limitadoras de perdas para as instituições financeiras, ou seja, a partir de um determinado valor de perdas acumulado, as instituições deixariam de comprar dólares das empresas. A principal vantagem em relação aos derivativos mais simples (plain vanilla), era a obtenção de taxa de câmbio de exercício mais vantajosa para a empresa exportadora - um grande diferencial competitivo em ambiente macroeconômico caracterizado por progressiva apreciação da taxa de câmbio.

Um exemplo numérico ajuda a entender o mecanismo de funcionamento do TARF/TARN do ponto de vista de um exportador com objetivo de fazer hedge. Em 2 de janeiro de 2008, o dólar estava cotado a $\mathrm{R} \$ 1,77$. Uma possibilidade seria travar essa taxa de câmbio com contratos a termo, de modo que os ganhos (perdas) com derivativos compensariam as perdas (ganhos) relativos à variação cambial. Uma alternativa seria contratar um TARF/TARN com preço de exercício um pouco maior, R\$ 1,85, a ser liquidado em duas parcelas semestrais, com cláusula que limita as perdas para as instituições financeiras em R \$ 0,15 por dólar. Para qualquer cotação do dólar inferior a R \$ 1,70 , o banco pagaria à exportadora $\mathrm{R} \$ 0,15$. Para taxas de câmbio entre $\mathrm{R} \$ 1,71$ e $\mathrm{R} \$ 1,85$, a exportadora ganharia a diferença entre a taxa de câmbio efetiva e o preço de exercício. Para taxas superiores a $\mathrm{R} \$ 1,85$, a exportadora pagaria à instituição financeira o dobro da variação cambial. Conforme se pode observar no Gráfico 2, os TARF/TARN resultavam em hedge com ganhos superiores aos contratos de derivativos padronizados para situações em que ocorresse apreciação moderada da taxa de câmbio. Caso a apreciação do real fosse muito expressiva, a proteção seria limitada. Por fim, caso o real tivesse grande depreciação frente ao dólar, as empresas teriam prejuízos com derivativos. Desse modo, por meio dos TARF/TARN as empresas exportadoras simultaneamente obtinham proteção contra uma apreciação cambial e especulavam contra uma depreciação cambial. 


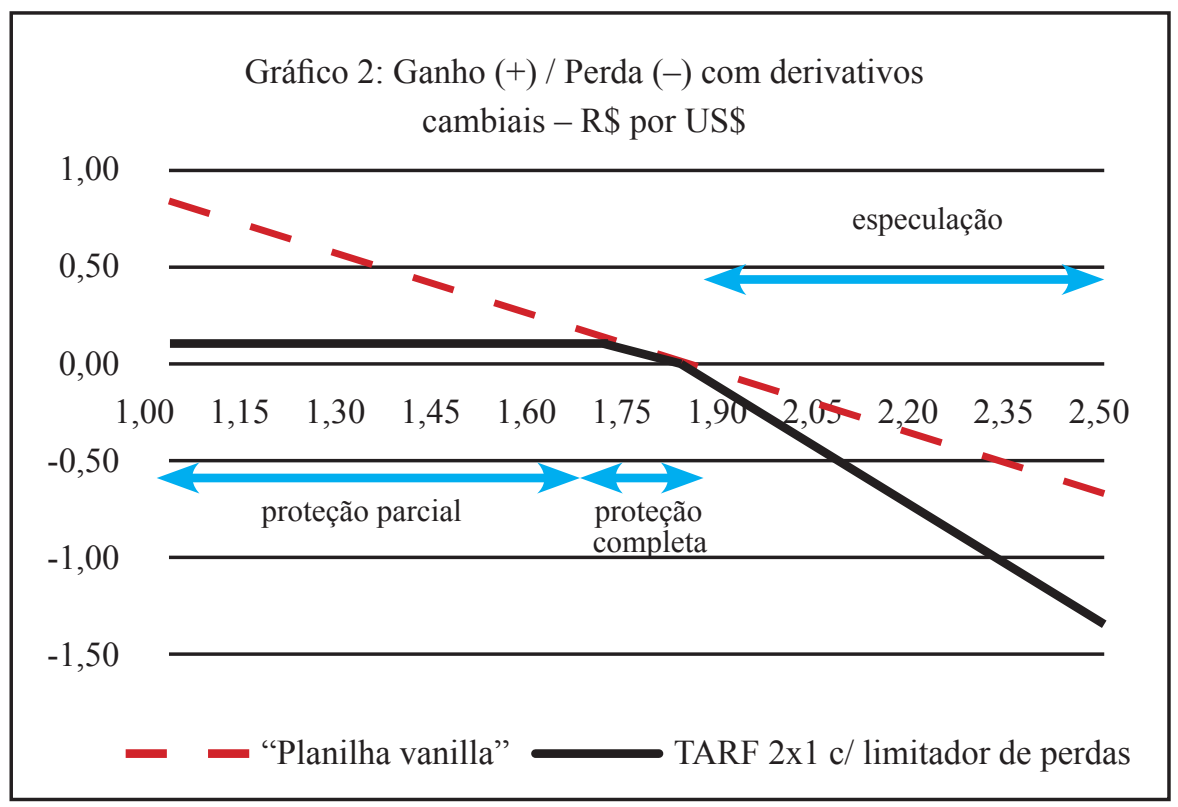

Fonte: Elaboração própria

Com a quebra do Lehmann Brothers, em setembro de 2008, houve forte depreciação cambial e o dólar terminou cotado a $\mathrm{R} \$ 2,34$ no final daquele ano, contra $\mathrm{R} \$$ 1,65 previstos poucos dias antes da quebra daquela instituição financeira. Com isso, os TARF/TARN, que fizeram parte de estratégias comerciais exitosas entre 2004 e agosto de 2008, passaram a acarretar pesados prejuízos para as exportadoras brasileiras. Estimase em 25 bilhões de dólares a perda das empresas brasileiras com derivativos cambiais (BANK FOR INTERNATIONAL SETTLEMENTS, 2009).

Há três possibilidades para que as empresas brasileiras, com destaque para os exportadores, tenham assumido elevados riscos com derivativos cambiais que resultaram em perdas de USD 25 bilhões: i. estratégia deliberada visando à obtenção de retornos mais elevados, com plena ciência de administradores e acionistas ${ }^{2}$ dos riscos incorridos; ii. estratégia deliberada visando à obtenção de retornos mais elevados, com plena ciência de, pelo menos, alguns administradores dos riscos incorridos, sem que os acionistas e eventualmente alguns administradores tenham plena convicção dos riscos incorridos; iii. as instituições financeiras ofertaram instrumentos financeiros inadequados

2 A análise também se aplica a empresas com sócios, embora nas sociedades limitadas as figuras de administradores e sócios tendem a se confundir. 
aos objetivos ou grau de tolerância ao risco das empresas sem informar adequadamente os administradores dos riscos incorridos.

No primeiro caso, há erro de estratégia empresarial, não se aplicando a revisão por excessiva onerosidade, pois a variação no preço do ativo subjacente é o próprio objeto do contrato. ${ }^{3}$ No segundo caso, ocorre um problema de agência, descrito na análise pioneira de Jensen \& Meckling (1976). Nestes casos, cabe responsabilização de administradores. Por fim, a depender da gravidade da falha no dever de prestar informações por parte das instituições financeiras, os administradores podem cometer erro substancial quanto ao risco assumido ou mesmo quanto à função do derivativo contratado $(\mathrm{CC}$, art. 139, I), tornando os contratos anuláveis.

\subsection{A jurisprudência}

A partir dos argumentos de pesquisa "derivativos", "swap", "opções flexíveis", "box" e "hedge", foram pesquisadas decisões judiciais relativas a contratos de derivativos publicadas até 31/08/2016 nos endereços eletrônicos do STJ, Tribunal de Justiça do Distrito Federal e Territórios (TJDFT) e nos 26 tribunais de justiça estaduais. Foram excluídas as decisões em que as palavras foram utilizadas em sentido diverso ao de derivativos financeiros (por exemplo: box comercial), em que se fazia mera referência os instrumentos derivativos e os embargos de declaração não conhecidos ou não providos, para evitar dupla contagem com as respectivas apelações. Com isso, foram encontradas 210 decisões, das quais $49(23,3 \%)$ relevantes aos propósitos deste artigo: 37 (17,6\%) dizem respeito à possibilidade de revisão ou resolução contratual de contratos derivativos, $4(1,9 \%)$ são referentes à responsabilidade de administradores nos vultosos prejuízos obtidos pela Sadia em 2008 e $8(3,8 \%)$ relativas a pleitos de anulação dos contratos em decorrência de falhas das instituições financeiras em informar os contratantes sobre os riscos dos negócios jurídicos realizados.

Das 37 decisões nas quais o aspecto discutido diz respeito a pedidos de revisão ou resolução contratual de derivativos em virtude de mudanças repentinas nas condições de mercado, $35(94,6 \%)$ têm como fato gerador a maxidesvalorização cambial de 2008, seguido da mudança de regime cambial em 1999 e dos efeitos da expressiva queda nas ações da Petrobras sobre contrato de swap no contexto da crise financeira mundial no segundo semestre de 2008, com 1 acórdão cada (2,7\%).

Neste sentido, o Enunciado 35 da I Jornada de Direito Comercial prescreve: "Não haverá revisão ou resolução dos contratos de derivativos por imprevisibilidade e onerosidade excessiva (arts. 317 e 478 a 480 do Código Civil)". 
Em todos os casos analisados, uma das partes era instituição financeira (IF) bancária. No polo oposto, empresas (35), cooperativa (1) e pessoa física (1). Das 35 disputas envolvendo relações empresariais, em apenas uma o CDC foi indevidamente aplicado a uma sociedade limitada exportadora de café, mas, ainda assim, se decidiu pelo não cabimento da revisão contratual. No recurso interposto por pessoa física, o CDC foi afastado porque o investidor tinha comprovada experiência com instrumentos derivativos. Nenhum tribunal acatou a tese da aplicabilidade dos arts. 478 a 480 do Código Civil aos derivativos, mesmo em se tratando da rápida mudança nas condições de mercado de setembro de 2008, sendo que 26 (70,3\%) decisões rejeitaram a aplicabilidade da revisão contratual aos contratos de derivativos - uma delas chegou ao STJ, que não conheceu o recurso com base nas Súmulas 5 e 7 .

Há 8 recursos em que as contrapartes não financeiras argumentam a desproporção de riscos para a contraparte financeira e não financeira nos contratos de TARF/TARN seria apta a gerar revisão contratual. Uma das decisões foi favorável à instituição financeira exatamente por reconhecer que risco menor para o banco corresponde a uma maior expectativa de retorno para investidor. Também houve três acórdãos da $14^{\mathrm{a}}$ Câmara de Direito Privado do TJSP que anularam julgamentos antecipados de primeira instância nos quais se acolhia o argumento de que as cláusulas limitadoras de perdas gerariam enriquecimento sem causa para o banco por "resultarem em riscos maquiados". O fundamento dessas três decisões é que a eventual desproporção de riscos demanda prova pericial.

Houve apenas $4(10,8 \%)$ provimentos - nenhum de mérito - contrários às instituições financeiras. Nesses casos, os tribunais consideraram que, pelo fato de derivativos serem contratos aleatórios, a alegação de desproporção de riscos em contratos de TARF/TARN dizia respeito ao mérito da sentença e, por essa razão, as instituições financeiras não poderiam inscrever as empresas em cadastros de devedores inadimplentes até a decisão final.

De todas as empresas que tiveram perdas elevadas com derivativos cambiais em 2008, a Sadia é o caso mais famoso e as 4 decisões (1 do STJ e 3 do TJSP) encontradas dizem respeito a processos movidos pelos acionistas da companhia visando à responsabilização do ex-diretor financeiro (3) e dos ex-gerentes financeiro e de tesouraria (1) por prejuízos com derivativos cambiais acarretados por contratos de TARF/TARN.

Em 06/04/2009, uma assembleia-geral extraordinária (AGE) decidiu pela autorização para ingresso com ação de responsabilidade civil contra ex-Diretor Financeiro. No dia 27/04/2009, a assembleia-geral ordinária (AGO) aprovou as contas da administração sem ressalvas.

Após essa AGO, a companhia ingressou com ações para responsabilizar o ex-Diretor Financeiro e os gerentes da área financeira por inobservância da política 
financeira da empresa por entenderem que a aprovação das contas sem ressalvas na AGO não teria alterado e modificado o conteúdo deliberado e aprovado expressamente na AGE. Os tribunais rejeitaram os pedidos com fundamento no $\S 3^{\circ}$ do art. 134 da Lei n. 6.404/76. ${ }^{4}$ A aprovação das contas sem ressalvas modificou a decisão da AGE e exonerou a responsabilidade do ex-Diretor financeiro e dos gerentes. Isso porque, quando a AGO ocorreu, já se tinha plena consciência dos prejuízos com derivativos cambiais.

Em processo administrativo sancionador, a CVM aplicou a pena de inabilitação temporária por três anos para exercício de cargo de administrador de companhia aberta ao ex-Diretor Financeiro da Sadia pelo fato de ele ter descumprido os limites de riscos da política financeira da companhia, já que a perda máxima aceitável pela empresa, calculada para um cenário de dólar cotado a $\mathrm{R} \$ 3,50$ - bastante superior às cotações verificadas, era menor que as perdas incorridas.

Além disso, a Autarquia aplicou multa pecuniária aos conselheiros e membros dos comitês de risco e de auditoria por falha no dever de diligência, pois eles tinham o dever de se informar sobre as informações prestadas pelo então Diretor Financeiro (BRASIL, 2010). O relator chamou a atenção para a frágil estrutura de governança da Companhia, na qual a área de gestão de riscos estava submetida à área operacional, não tendo independência suficiente.

Finalmente, há 8 decisões em que a contraparte não financeira alegou nulidade contratual porque as instituições financeiras teriam falhado no dever de informálas sobre os riscos da contratação - em 2 delas, alegou-se nulidade dos contratos porque o intermediário financeiro teria realizado contratos com finalidade especulativa em vez de hedge. Todos os casos envolveram derivativos cambiais e o fato gerador foram altas do dólar - 5 (62,5\%) em 2008 e 3 (37,5\%) referente à mudança de regime cambial em 1999.

Todas as decisões foram favoráveis às instituições financeiras porque os tribunais entenderam não ter havido comprovação de que as instituições financeiras descumpriram com o dever de informar. Entre as provas admitidas para comprovar o cumprimento do dever de informar, estão o histórico de relacionamento entre instituição financeira e cliente, gravações telefônicas em que se comprova a ciência quanto aos riscos contratados e a demonstração de que os contratos de derivativos, apesar de resultarem em saldo negativo expressivo, foram adquiridos para fazer hedge em um financiamento, resultando em juros mais baixos. Em um julgado a sentença foi anulada de ofício porque saber se o contrato tinha finalidade especulativa ou de hedge demanda prova pericial. Aliás, a dificuldade em se determinar se instrumentos de TARF/TARN têm finalidade especulativa ou protetiva fundamentou uma decisão que suspendeu efeitos da sentença

4 A aprovação, sem reserva, das demonstrações financeiras e das contas, exonera de responsabilidade os administradores e fiscais, salvo erro, dolo, fraude ou simulação. 
arbitral por haver dúvidas quanto à natureza do instrumento submetido ao juízo arbitral (SÃO PAULO, 2005).

\subsection{Um problema sistêmico e internacional}

Ao analisar os efeitos da crise de 2008 no mercado de derivativos cambiais, Werther Vervloet e Márcio Garcia (2010) citam diversos casos de empresas exportadoras com problemas similares ao da Sadia: derivativos cambiais do tipo TARF/TARN que vinham sendo realizados com fins de hedge e que se mostraram ruinosos. Além disso, também citam o caso da Tok\&Stok, empresa de médio porte que contratou empréstimos em dólares e, para se proteger da depreciação do real, realizou negócios de hedge cambial que acabaram resultando em prejuízo de $\mathrm{R} \$ 55$ milhões.

Como não se trata de empresa exportadora, ou seja, a Tok\&Stok não possui receitas em moeda estrangeira, restou evidente a inadequação dos derivativos contratados para realizar o hedge. Os autores também mencionam que a empresa processou o Banco Itaú BBA, que estruturou as operações e uma das decisões do subitem 5.3 em que o TJSP anulou decisão sumária de primeira instância porque a alegação de desproporção de riscos demandava prova pericial dizia respeito à Tok\&Stok.

Ao se debruçarem sobre a crise com derivativos cambiais nas empresas brasileiras em 2008, Bacic et al. (2010, p. 46-68) concluem que, além dos aprimoramentos nas regras contábeis e requisitos de governança, é necessário que as áreas financeiras das empresas sigam o conjunto de princípios operacionais e estratégicos definidos para o resto da organização, engajando-se na visão estratégica de longo prazo das corporações. Fornazier et al. (2011), por sua vez, ressaltam que as inovações financeiras, como os derivativos, criam necessidade de constantes atualizações da regulação, pois os agentes tendem a criar mecanismos para fugir das imposições estabelecidas pela regulação.

Tal problema não se restringiu ao Brasil - contratos similares a TARF/ TARN também geraram vultosos prejuízos em países desenvolvidos. Em geral esses contratos tinham como ativo subjacentes taxas de juros e visavam à proteção contra altas das taxas de juros em contratos indexados a juros flutuantes. Na Itália, Roppo (2013, p. 957-988) relata que diversos governos regionais e locais realizaram negócios jurídicos com derivativos de cunho especulativo, claramente inadequados ao perfil da administração pública e que tribunais anularam tais contratos. O Supremo Tribunal de Justiça de Portugal aplicou revisão contratual por alteração das circunstâncias em decorrência da queda de juros que ocorreu após a crise de 2008 na Europa. Os fundamentos da decisão foram criticados por Gonzalez e Ventura (2014, p. 86), por entenderem que a revisão por alteração das circunstâncias não se aplica aos derivativos e que o problema central foi a falha da instituição financeira de informar a contraparte dos riscos da contratação. 
Neste caso, portanto, uma incompreensão do real problema levou a uma decisão com fundamento equivocado. Nos Estados Unidos, a Comissão de Investigação sobre a Crise Financeira constatou que uma das causas da crise foi a oferta de instrumentos financeiros complexos inadequados ao perfil dos contratantes (UNITED STATES OF AMERICA, 2011).

5.5. Uma visão alternativa da crise de 2008 a partir da economia comportamental

No item 4, foram apresentados o que, para Thaler e Sunstein (2008) seriam indícios de insuficiência da abordagem econômica convencional. Nos negócios jurídicos com instrumentos financeiros complexos ${ }^{5}$ - e derivativos de balcão do tipo TARF/TARN certamente se enquadram no conceito de instrumentos financeiros complexos - todos esses indícios estão presentes:

i. Há grande flexibilidade para que os instrumentos financeiros complexos se adequem a diferentes perfis negociais e de apetite ao risco. Por essa razão, além da variedade, há inúmeras configurações possíveis. Se por um lado isso permite ganhos de eficiência, por outro dificilmente esses instrumentos possuem mercado secundário e a precificação depende de cálculos complexos;

ii. Nas empresas não financeiras, a estruturação de operações financeiras tem custo elevado e não é o core business, de modo que a escolha dos instrumentos financeiros não é frequente - uma vez escolhido um determinado instrumento, ele tende a ser contratado sucessivas vezes;

iii. Como em todo instrumento financeiro, há um trade-off entre risco e retorno. Por serem mais flexíveis, os instrumentos financeiros costumam produzir mais benefícios no curto prazo, o que é compensado por maiores riscos no longo prazo;

iv. Como visto com os TARF/TARN, o resultado com instrumentos financeiros complexos em períodos de normalidade é completamente diferente do que ocorre em momentos de crise. Embora a jurisprudência acolha o argumento de que a experiência prévia demonstre ciência quanto aos riscos assumidos, a presunção deve ser relativa, pois a

\footnotetext{
De acordo com a International Organization of Securities Commissions (IOSCO), produtos financeiros complexos são instrumentos financeiros de difícil compreensão devido à estrutura complexa e dificuldade de precificiação. A categoria exclui ações e derivativos mais simples negociados em bolsas. IOSCO: International Organization of Securities Commissions. Suitability requirements with respect to the distribution of complex financial products. Final report. Jan. 2013. Disponível em: <http://www.iosco.org/ library/pubdocs/pdf/IOSCOPD400.pdf>.
} 
experiência acumulada entre 2004 e 2008 foi pouco relevante durante a crise;

v. Muitas empresas sequer possuem procedimentos para definir o grau de tolerância ao risco, ou seja, possuem dificuldades em conhecer a própria vontade;

vi. Mesmo quando os agentes definem o grau de tolerância ao risco, há grande dificuldade em se escolher instrumentos financeiros adequados ao grau de tolerância ao risco.

Por essa razão, não é de se surpreender que a crise de 2008 evidenciou algumas hipóteses da economia comportamental, com destaque para o otimismo, o viés inercial e o comportamento de manada. $\mathrm{O}$ acentuado otimismo (subitem 3.1.2) dos agentes de mercado nos anos que precederam a crise fez com que muitos subestimassem os riscos dos derivativos contratados. Nos Estados Unidos e na Europa não se esperava uma queda expressiva das taxas de juros, embora o Federal Reserve (FED) tenha baixado os juros rapidamente entre o final de 2000 e 2001 para mitigar os efeitos negativos da crise no mercado acionário e o Japão convivesse há mais de uma década com taxas de juros próximas de zero. No Brasil, embora as maxidesvalorizações cambiais de 1999 e 2002 fossem eventos relativamente recentes, as empresas que contrataram TARF/TARF agiram como se uma nova maxidesvalorização do real fosse um evento altamente improvável. Em outras palavras, embora no médio prazo houvesse histórico que respaldasse a crença de que movimentos bruscos e adversos de mercado poderiam ocorrer, predominou o sentimento de que "desta vez será diferente".

Outro aspecto relevante foi a inércia (subitem 3.1.3): nos anos que antecederam a crise de 2008, o cenário era de queda de juros nos países centrais e progressiva apreciação cambial no Brasil (e países emergentes em geral) fizeram dos derivativos TARF/TARN uma alternativa mais lucrativa que os derivativos mais comuns para hedge ou a simples não realização de hedge. Com isso, no Brasil a lucratividade de empresas exportadoras foi preservada e, nos países desenvolvidos, os agentes endividados puderam aumentar o grau de alavancagem, mesmo com aumento nas taxas de juros.

Foi marcante também a influência social e o comportamento de manada (subitem 3.3). A partir do momento em que empresas brasileiras líderes em exportações realizavam operações com derivativos cambiais e vinham obtendo bons resultados, isso passou um sinal para que empresas menores e com departamentos financeiros menores fizessem a mesma estratégia. Além disso, mesmo que essa sinalização não ocorresse, a própria pressão competitiva forçaria empresas a assumirem posturas financeiras mais especulativas - afinal, as empresas que não fizeram hedge com derivativos cambiais antes da crise foram menos lucrativas e, com isso, tenderam a perder mercado para as demais. $\mathrm{O}$ mesmo se pode dizer do endividamento privado nos países desenvolvidos. Por 
isso, muitos agentes em posição de vantagem informacional - instituições financeiras e administradores da área financeira - irão se portar como phisers, explorando deficiências cognitivas e emocionais dos phools (item 4).

No subitem 5.3 vimos que a jurisprudência, ao rejeitar pedidos de anulação contratual com o fundamento que a experiência prévia com contratos derivativos - mesmo que em conjuntura completamente diferente da crise de 2008 - evidencia que as empresas tinham plena ciência dos riscos, assume, ao menos implicitamente, que os agentes são dotados de racionalidade forte, ignorando vieses comportamentais, comportamento de manada e a possibilidade de isso ser explorado economicamente por outros agentes.

\section{Considerações finais}

A hipótese da racionalidade forte, que permeia a análise econômica convencional, também está implícita nas normas e nas decisões dos tribunais. Elementos tidos como não racionais costumam ser considerados desvios aos padrões de condutas. Isso é importante para dar previsibilidade aos mercados, reduzindo custos de transação, e é um dos pilares fundamentais do Direito Comercial.

Por outro lado, a economia comportamental constata que muitas dessas condutas tidas como não racionais ou desviantes são, na verdade, inerentes aos seres humanos, falseáveis por estudos empíricos e passíveis de sistematização. Embora deficiências informacionais, vieses cognitivos e emocionais e comportamento de manada exerçam forte influência nas condutas dos agentes econômicos e resultem muitas vezes em erros sistemáticos, isso não deve ser visto como obstáculo para a responsabilização dos agentes econômicos pelos seus erros. O que se propõe é que as contribuições da economia comportamental sejam levadas em conta pelos legisladores e reguladores, de forma a incentivar comportamentos socialmente desejáveis e fornecer ferramentas para que os tribunais tenham uma visão mais completa dos casos.

$\mathrm{O}$ estudo da crise com derivativos financeiros em 2008 oferece subsídios para essa empreitada. Mais que erro nas estratégias de algumas empresas isoladas, os expressivos prejuízos com derivativos financeiros foram fruto de uma estratégia disseminada entre as principais empresas exportadoras brasileiras e teve paralelo com o que aconteceu em países desenvolvidos. A resposta do judiciário foi negar os pedidos de revisão contratual ou de nulidade dos contratos porque as empresas deveriam ter avaliado os riscos desses contratos. A resposta dos reguladores foi no sentido de diminuir as assimetrias de informação. Mesmo de posse de informações mais precisas, a atual regulação não atua nos elementos comportamentais que resultaram na crise.

São Paulo, atualizado em março de 2018. 


\section{Referências}

AKERLOF George A.; SHILLER, Robert J. Phishing for phools: the economics of manipulation and deception. Princeton: Pinceton University Press, [2015].

AXELROD, Robert M. The evolution of cooperation. New York, Basic Books, 1984.

BACIC, Miguel Juan; DA SILVEIRA, Rodrigo Lanna Franco; FERREIRA DE SOUZA, Maria Carolina de Azevedo. Gestão imprudente do risco financeiro como elemento de destruição de valor: uma reflexão a partir do uso de derivativos por empresas líderes brasileiras. Revista Digital del Instituto Internacional de Costos, n. 6, p. 49-68, enero/junio 2010. Disponível em: <http://www. revistaiic.org/articulos/num6/articulo3_esp.pdf>.

BCB: Banco Central do Brasil. Focus: Relatório de Mercado. Brasília, DF, 12 de setembro de 2008. Disponível em: <https://www.bcb.gov.br/pec/GCI/PORT/readout/R20080912.pdf>.

BIS: Bank for International Settlements. A glossary of terms used in payment and settlement systems. Basel: Committee On Payment And Settlement Systems, Mar. 2003. Disponível em: $<$ http://www. bis.org/publ/cpss00b.pdf>.

BIS: Bank for International Settlements. BIS Quarterly Review: International banking and financial market developments. Basel: Monetary And Economic Department, June 2009. Disponível em: $<$ https://www.bis.org/publ/qtrpdf/r_qt0906.pdf $>$.

BRASIL. Comissão de Valores Mobiliários. Processo Administrativo Sancionador n. 18/08. Relator: Diretor Alexsandro Broedel Lopes. Diário Oficial da União, Brasília, DF, 27 out. 2010.

BRASIL. Lei n. 12.543, de 8 de dezembro de 2011. Autoriza o Conselho Monetário Nacional, para fins de política monetária e cambial, a estabelecer condições específicas para negociação de contratos derivativos. Diário Oficial da União, Brasília, DF, 9 dez. 2011.

BRASIL. Lei n. 13.105, de 16 de março de 2015. Código de processo civil. Diário Oficial da União, Brasília, DF, 17 mar. 2015.

BRASIL. Lei n. 6.385, de 7 de dezembro de 1976. Dispõe sobre o mercado de valores mobiliários e cria a Comissão de Valores Mobiliários. Diário Oficial da União, Brasília, DF, 9 dez. 1976.

BRASIL. Lei n. 8.955, de 15 de dezembro de 1994. Dispõe sobre o contrato de franquia empresarial (franchising) e dá outras providências. Diário Oficial da União, Brasília, DF, 16 dez. 1994.

BRASIL. Superior Tribunal de Justiça. Esclarecimento sobre tabela de precedentes de dano moral. Brasília, DF, 13 set. 2009. Disponível em: <http://stj.jusbrasil.com.br/noticias/1885586/ esclarecimento-sobre-tabela-de-precedentes-de-dano-moral>. Acesso em: 18 mar. 2018.

BRASIL. Superior Tribunal de Justiça. Reclamação n. 5.685/RJ. Relator: Ministro Mauro Campbell Marques, Data de Julgamento: 10/08/2011. Diário da Justiça. Brasília, DF, 2011a. 
BRASIL. Superior Tribunal de Justiça. Recurso Especial n. 1.424.814/SP. Relator: Ministro Marco Aurélio Bellizze, Data do julgamento: 04/10/2016. Diário da Justiça. Brasília, DF, 2016.

BRASIL. Superior Tribunal de Justiça. Recurso Especial n. 959780/ES. Relator: Ministro Paulo de Tarso Sanseverino, Data do julgamento: 26/04/2011. Diário da Justiça. Brasília, DF, 2011 b.

CHAPMAN, Gretchen B.; BORNSTEIN, Brian H. The more you ask for, the more you get: anchoring in personal injury verdicts. Applied Cognitive Psychology, v. 10, n. 6, p. 519-540, 1996. Disponível em: $<$ https://www.researchgate.net/profile/Gretchen_Chapman/publication/229452292_ The_More_You_Ask_for_the_More_You_Get_Anchoring_in_Personal_Injury_Verdicts/ links/55883f1708aeb716bccfe97f.pdf $>$.

DEMOGRAFIA das empresas: 2014. Estudos e pesquisas. Informação econômica, Rio de Janeiro, n. 27, 2016. Disponível em: <http://biblioteca.ibge.gov.br/visualizacao/livros/liv98073.pdf>.

DOVERN, Jonas; JANNSEN, Nils. Systematic errors in growth expectations over the business cycle. Kie: Kiel Institute for the World Economy, Feb. 2015. Disponível em: <https://www.ifwmembers.ifw-kiel.de/publications/systematic-errors-in-growth-expectations-over-the-businesscycle/systematic-errors-in-growth-expectations-over-the-business-cycle>.

DRAHOZAL, Christopher R. A behavioral analysis of private judging. Law and contemporary problems, v. 67, n. 1, p. 105-132, Winter 2004. Disponível em: <https://scholarship.law.duke.edu/ lcp/vol67/iss $1 / 5 />$.

EVERETT, Jim A. C.; PIZARRO, David A.; CROCKETT, M. J. Inference of trustworthiness from intuitive moral judgments. Journal of Experimental Psychology: General, v. 145, n. 6, p. 772-787, Jun. 2016. Disponível em: <https://www.apa.org/pubs/journals/features/xge-xge0000165.pdf>.

FORGIONI, Paula Andrea. Contratos empresariais: teoria geral e aplicação. 2. ed., rev., atual. e ampl. São Paulo: Revista dos Tribunais, 2016. p. 85.

FORNAZIER, Armando; PORTUGAL JÚNIOR, Pedro dos Santos; MADI, Maria Alejandra Caporale. Condicionantes macroeconômicos da tomada de decisão nas empresas não-financeiras no Brasil: uma análise no contexto da crise de 2008. In: Encontro Internacional da Associação Keynesiana Brasileira, 4, 2011. Rio de Janeiro. Anais... Rio de Janeiro: AKB, 2011.

GIRINO, Emilio. I contratti derivati. 2. ed. Milano: Giuffrè Editore, 2010. p. 26-31 e 271-278.

GONZALEZ, Pedro; VENTURA, João. Contrato de swap e alteração de circunstâncias: anotação ao acórdão do Supremo Tribunal de Justiça, processo n. 1.387/11.5TBBCL.G1.S1. Cadernos do Mercado de Valores Mobiliários, Lisboa, n. 48, p. 63-87, ago. 2014. p. 86. Disponível em: <http:// www.cmvm.pt/pt/EstatisticasEstudosEPublicacoes/CadernosDoMercadoDeValoresMobiliarios/ Documents/CadernosMVM\%2048d.pdf>.

HODGSON, Geoffrey Martin. From pleasure machines to moral communities: an evolutionary economics without homo economicus. Chicago London: University of Chicago Press, 2013. 
HULL, John C. Fundamentos dos mercados futuros e de opções. Tradução Marco Aurélio Teixeira. 4. ed. rev. e ampl. São Paulo: Bolsa de Mercadorias e Futuros, 2005.

IBGE: Instituto Brasileiro de Geografia e Estatística. Demografia das empresas: 2014. Coordenação de Metodologia das Estatísticas de Empresas, Cadastros e Classificações. Rio de Janeiro: IBGE, 2016. (Estudos e pesquisas. Informação econômica, n. 27). Disponível em: < https://biblioteca.ibge. gov.br/visualizacao/livros/liv98073.pdf>.

IOSCO: International Organization of Securities Commissions. Suitability requirements with respect to the distribution of complex financial products. Final report. Jan. 2013. Disponível em: $<$ http://www.iosco.org/library/pubdocs/pdf/IOSCOPD400.pdf $>$.

JENSEN, Michael C.; MECKLING, William H. Theory of the firm: managerial behavior, agency costs and ownership structure. Journal of Financial Economics, v. 3, n. 4, p. 305-360, Oct. 1976.

KAHAN, Marcel; KLAUSNER, Michael. Path dependence in corporate contracting: increasing returns, herd behavior and cognitive biases. Washington University Law Review, Washington, v. 74, n. 2, p. 347-366, Jan. 1996. Disponível em: $<$ https://openscholarship.wustl.edu/cgi/viewcontent.cgi ?referer $=\&$ httpsredir $=1 \&$ article $=1607 \&$ context=law_lawreview $>$.

KAHNEMAN, Daniel. Rápido e devagar: duas formas de pensar. Tradução Cássio de Arantes Leite. Rio de Janeiro: Objetiva, 2012.

KOROBKIN, Russell. The status quo bias and contract default rules. Cornell Law Review, Ithaca, NY, v. 83, n. 3, p. 608-687, Mar. 1998. Disponível em: <http://scholarship.law.cornell.edu/cgi/ viewcontent.cgi? article $=2721 \&$ context $=\mathrm{clr}>$.

MINAS GERAIS. Tribunal de Justiça de Minas Gerais. Apelação Cível n. 10027100163669001/ MG. Relator: Desembargador Márcio Idalmo Santos Miranda. Data de Julgamento: 21/07/2015. Diário Oficial, Minas Gerais, 2015.

NORTHCRAFT, Gregory B.; NEALE, Margaret A. Experts, amateurs, and real estate: an anchoringand-adjustment perspective on property pricing decisions. Organizational Behavior and Human Decision Processes, v. 39, p. 84-97, 1987.

PINDYCK, Robert S.; RUBINFELD, Daniel L. Microeconomia. Tradução e revisão técnica Eleutério Prado. 6. ed. São Paulo: Pearson Prentice Hall, 2005.

ROPPO, Vincenzo. Confronto con la giurisprudenza. Rivista di Diritto Civile, Padova, v. 4, p. 957988, 2013.

SÃO PAULO. Tribunal de Justiça de São Paulo. Agravo de Instrumento n. 214545489.2014.8.26.0000. Relator: Desembargador Miguel Petroni Neto. Diário de Justiça do Estado de São Paulo, São Paulo, 2005. 
SÃO PAULO. Tribunal de Justiça. Apelação Cível n. 4006042-13.2013.8.26.0302. Relator: Desembargador Coelho Mendes. São Paulo, 13 fev. 2014. Diário da Justiça Eletrônico do Estado de São Paulo, São Paulo, 2015.

SEBRAE: Serviço Brasileiro de Apoio às Micro e Pequenas Empresas. Causa Mortis: o sucesso e o fracasso das empresas nos primeiros cinco anos de vida. São Paulo, jul. 2014. Disponível em: $<$ https://www.sebrae.com.br/Sebrae/Portal\%20Sebrae/UFs/SP/Pesquisas/causa_mortis_2014.pdf $>$.

SHAROT, Tali. O viés otimista: por que somos programados para ver o mundo pelo lado positivo. Tradução de Ana Beatriz Rodrigues. 1. ed. Rio de Janeiro: Rocco, 2015.

THALER, Richard H.; SUNSTEIN, Cass R. Nudge: improving decisions about health, wealth and happiness. New Haven: Yale University Press, 2008.

TVERSKY, Amos; KAHNEMAN, Daniel. The framing of decisions and the psychology of choice. Science, New Series, v. 211, n. 4.481, p. 453-458, Jan. 1981.

UNITED STATES OF AMERICA. The Financial Crisis Inquiry Commission. The financial crisis inquiry report: final report of the national commission on the causes of the financial and economic crisis in the United States. Washington: U.S. Government Printing Office, 2011. 663 p. Disponível em: <https://www.gpo.gov/fdsys/pkg/GPO-FCIC/pdf/GPO-FCIC.pdf>.

VERVLOET, Werther Teixeira de Fretas. Efeitos de intervenções esterilizadas do Banco Central do Brasil sobre a Taxa de Câmbio. 2010. Dissertação (Mestrado) - Departamento de Economia, Pontifícia Universidade Católica do Rio de Janeiro, Rio de Janeiro, 2010. 